\title{
Physical and Physiological Characteristics of Cameroon Professional Soccer Players According to Their Competitive Level and Playing Position
}

\author{
Jean Fomini Tendonkeng ${ }^{1,2}$, Telesphore Benoit Nguelefack ${ }^{1}$, Peguy Brice Assomo Ndemba ${ }^{2,5}$, \\ Wiliam Richard Guessogo ${ }^{2,3}$, Jerson Mekoulou Ndongo ${ }^{2}$, Abdou Temfemo ${ }^{2,4,6, *}$ \\ ${ }^{1}$ Department of Animal Biology, Faculty of Sciences, University of Dschang, Dschang, Cameroon \\ ${ }^{2}$ Exercise and Sport Physiology Unit, Faculty of Science, University of Douala, Douala, Cameroon \\ ${ }^{3}$ Department of Biology, National Institute of Youth and Sports, Yaounde, Cameroon \\ ${ }^{4}$ Department of Biological Science, Faculty of Medicine and Pharmaceutical Sciences, University of Douala, Cameroon \\ ${ }^{5}$ Department of Physiology, Faculty of Medicine and Biomedical Sciences, University of Yaounde I, Yaounde, Cameroon \\ ${ }^{6}$ EA 3300 Physiological Adaptations to Exercise and Rehabilitation to Effort, Faculty of Sport Sciences, University of Picardie Jules Verne, \\ Amiens, France
}

Email address:

temfemo@hotmail.com (A. Temfemo)

${ }^{*}$ Corresponding author

\section{To cite this article:}

Jean Fomini Tendonkeng, Telesphore Benoit Nguelefack, Peguy Brice Assomo Ndemba, Wiliam Richard Guessogo, Jerson Mekoulou Ndongo, Abdou Temfemo. Physical and Physiological Characteristics of Cameroon Professional Soccer Players According to Their Competitive Level and Playing Position. International Journal of Sports Science and Physical Education. Vol. 6, No. 1, 2021, pp. 8-16. doi: $10.11648 /$ j.ijsspe.20210601.12

Received: March 2, 2021; Accepted: March 13, 2021; Published: March 22, 2021

\begin{abstract}
The present study aimed to determine the physical performances and physiological aptitudes of the soccer players of the first (L1) and second (L2) leagues of the Cameroon professional championship. One hundred and seventy-five male professional soccer players, including 91 from L1and 84 from L2, participated in the study. Their age, anthropometric parameters (height and weight), physical performances (short-distances sprint times, squat jump) and physiological parameters such as maximum oxygen consumption $\left(\mathrm{VO}_{2 \max }\right)$, blood lactate accumulation (BLA) and heart rate (HR) were assessed. No significant age difference was observed between of L1 and L2 (23.3 \pm 3.6 vs $23.64 \pm 1.00$ years) soccer players. L1 soccer players were taller and heavier than those of L2. According to the playing position, a significant difference in weight (76.0 \pm 7.6 vs $72.2 \pm 8.2 \mathrm{~kg})$ and height $(179.1 \pm 7.2 \mathrm{vs} 175.8 \pm 7.3 \mathrm{~cm})$ was observed between L1 and L2 midfield players. $\mathrm{VO}_{2 \max }$ of $\mathrm{L} 2$ players $\left(56.4 \pm 6.9 \mathrm{mlO}_{2} / \mathrm{L} / \mathrm{kg}\right)$ was better than that of $\mathrm{L} 1$ players $\left(53.8 \pm 4.3 \mathrm{mlO}_{2} / \mathrm{L} / \mathrm{kg}\right)$, as well as the BLA $(8.2 \pm 2.3 \mathrm{vs} 9.7 \pm 2.9$ $\mathrm{mmol} / \mathrm{L})$. L2attackers showed significant higher $\mathrm{VO}_{2 \max }(p<0.05)$ compared to $\mathrm{L} 1$ players at the same position. The BLA rate was higher $(p<0.01)$ in midfielders compared to defenders or attackers in each league. Soccer players of L1 were heavier, taller and had better physical aptitude with lower physiological response compared to those of L2. Globally, male Cameroon professional soccer players have average age of $23.4 \pm 3,8$ years; high of $177.4 \pm 7,2 \mathrm{~cm}$ and weight $74.1 \pm 7.9 \mathrm{~kg}$. These findings suggest that male Cameroon professional soccer players have good physical characteristic but lower physiological aptitudes. This may explain the poor performance of local teams during international competitions.
\end{abstract}

Keywords: Cameroon Professional Leagues, Soccer Players, Playing Position, Physical and Physiological Parameters

\section{Introduction}

Soccer is an intermittent and high-intensity team sport where the players are required to perform considerable physical and energy demand activities during a match [1,2]. The practice of modern soccer is deeply linked to the 
consideration of a certain number of physiological determinants which can be regularly improved by training. For instance, the maximal oxygen consumption $\left(\mathrm{VO}_{2 \max }\right)$ quantifies the aerobic capacity in each soccer player $[3,4]$ andit has been suggested that soccer players with $\mathrm{VO}_{2 \max }$ values superior to $60 \mathrm{ml} \cdot \mathrm{kg}^{-1} \cdot \mathrm{min}^{-1}$ could be competitive at the highest levels in soccer [5]. Blood lactate concentration (BLA) is another parameter that helps evaluating the endurance and the physical recovery of a player [6]. Therefore, determining $\mathrm{VO}_{2 \max }$ and BLA in soccer players is useful when assessing talent. Physiological characteristicof soccer players in the African championships is not yet sufficiently studied [7]. However, some studies were made to describe the anthropometric and motor characteristics of South African national level female soccer players [7]; to gain an understanding of the anthropometric and physical fitness characteristics of a group of competitive, semiprofessional footballers during their pre-season training period [8] and to examine characteristics of male South African university soccer players [9].

Most of the time, physical or technical qualities of soccer players are only taken in to consideration during selection. Thus, African soccer players are generally recruited in different clubs because they demonstrate certain physical anthropometric characteristics (height and weight) or performance in certain playing positions: attacker (dribbling, address, velocity); midfielder (conservation of the ball and orientation of the game), defender (size, strength, conquest on the ground and aerial duels) and goalkeeper (air and ground stops).

Low representation of the "local" players in the national Cameroon team qualified for competitions like the African Cup of Nations (CAN) or the world cup was even observed compared to that of their congeners who play in the Caucasian championships. Coton Sport of Garoua at the head of the first (L1) league of the Cameroon professional championship for more than 15 years has accumulated only repetitive failures during continental competitions (Champions League of African clubs). But yet, this team has older, bigger, heavier, faster, enduring and more powerful players than those of the middle and the bottom ranking teams [10]. These observations added to the fact that studies made in Africa were even in South Africa or in Maghreb. Having regard to all of the above and taking into account that most of the research carried out in Africa has been carried out either in South Africa or in North Africa; Central Africa remains very little explored, we set out to conduct this study to assess the physical aptitudes and physiological responses of local soccer playersin first league (L1) and second league (L2) of the Cameroon professional soccer championship.

\section{Methods}

The male Cameroon soccer professional championship is made up of L1 and L2. The present study was carried out during the 2017-2018 session and included 175 soccer players. Ninety-one (91) soccer players (age 23.3 \pm 3.6 years) were selected from the three different national L1clubs of Cameroon (Coton sport of Garoua, APEJES of Mfou and Aigle royal of Menoua) and 84 soccer players (age 23.6 \pm 4.1 years) were from three national L2 clubs (Ngaoundere University club, Cosmos of Mbam and Racing club of Bafoussam). Teams were selected based on their wiliness to participate on the study, their geographic positions and their performances during the previous seasons. In fact, in each league, the first club was from the top, the second from the middle and the third from the bottom. Concerning the geographic position, one club was from the north region, another from the west region and the last from the center region. All the main field positions were represented: goalkeepers (GK, 25), defenders (DF, 49), midfielders (MF, 49) and attackers (AT, 45). Participants were informed on the study aims, benefits, risks, procedures and they provided written informed consent before being enrolled in the study. The study was conducted following the recommendations of Helsinki as amended in 2013.

Soccer players attended more than five 90minutes training sessions per week. The testing procedures were performed at the end of the preparation period of seasons 2017-2018. Soccer players presenting no injury or illness during the data collection and free from subjective symptoms that could interfere with their performances participated in this study. They were instructed to consume a meal of their choice, similar as that they used before matches, 2-3 hours prior to each testing session. After collecting the age, body mass was taken at the nearest $1 \mathrm{~g}$ with an electronic scale (Tanita electronic scale BC-601) and height was measured with a standard stadiometer at the nearest $\mathrm{mm}$. Physical fitness tests were conducted on the field the same day and consisted of a vertical jump, sprint tests, and aerobic test. Each player was submitted to a 10-15 minutes standardized warm-up before completing the vertical jump, following by the sprint tests, and aerobic test separated by 5 minutes resting period. Player was encouraged to give maximum efforts during each test.

The assessment of Cameroon professional soccer playersfitness was done by measuring the heart rate at the following three times: at rest P1; immediately after effort P2; after one minute of recovery $\mathrm{P} 3$. These measurements were performed using a Beurer ME90 ECG mobile electrocardiogram. This device allowed obtaining in less than 5 seconds the value of the heart rate. The subject was sitting, in a state of rest; the heart rate was taken at rest. Then he performs the Ruffier test of 30 flexions-extensions on the legs during 45 seconds using and metronome. The feet lay on the ground, and the breath was freely natural. As soon as the Ruffier test was over, the subject immediately returned to his initial position and without waiting, the heart rate was taken again. Then, the subject recovered for one minute, before the last measurement of the heart rate. The Ruffier index was calculated from these three cardiac frequencies according to the formula: Ruffier index $=[(\mathrm{P} 1+\mathrm{P} 2+\mathrm{P} 3)-200] / 10$. The assessment of fitness for adaptation to the effort is made by relying on the scale of Ruffier and Dickson.

The speed ability of the subjects was assessed during 10, 
20, 30and $40 \mathrm{~m}$ sprint, by adopting the standard procedure [11]. One minute of recovery while walking was respected between two successive sprints of the same distance. Then five minutes of recovery between two different distances. The best time on each distance was retained for the analyses.

Vertical jumping ability was assessed using the squat jump SJ [12]. A static position with a $90^{\circ}$ knee flexion angle was maintained for 2 sconds before a jump attempt without any preparatory movement. To realize this test, player stood side on to a wall, keeping the feet flat on the floor, reached up as high as possible with one hand and marks the wall with the tips of the fingers using a chalk. This point marked served as the standing reach point. Then from a squatting position and away from the wall, participant jumped vertically as high as possible and marks another point (jump point) on the wall with a chalk. The difference in height between both points was measured to the nearest centimeters $(\mathrm{cm})$ using a calibrated stick. The average and peak of power values of the lower limbs were calculated using the following formulas: Peak of power $=61.1 \times \mathrm{Y}+36 \times \mathrm{P}+1822$. Average power $=$ $21.2 \times \mathrm{Y}+23 \times \mathrm{P}-1393$ with $\mathrm{Y}=$ score vertical jump, and $\mathrm{P}=$ weight [13].

Maximum aerobic power $\left(\mathrm{VO}_{2 \max }\right)$ was assessed by using an indirect method of multistage fitness test (Beep test) [14] from where $\mathrm{VO}_{2 \max }$ and the maximum aerobic speed (MAS) were predicted. It is a progressive shuttle run test for the prediction of aerobic fitness as well as to estimate a person's $\mathrm{VO}_{2 \max }$ from the standard chart. The procedures and purpose of the above test were elaborately instructed to all the players.
Typically the scores in the test are expressed as levels and shuttles, which estimate a person's $\mathrm{VO}_{2 \max }$.

The BLA was measured at rest and at 3 minutes after stopping the endurance test. For this measure of BLA, we used Lactate Scout LT 1730 ARKRAY [15] which allows accurate measurement of lactate levels in less than 60 seconds.

\section{Statistical analysis}

Quantitative variables were expressed as mean \pm standard deviation. The statistics program XLSTAT 2015.6.01.25740 was used for statistical analysis. Analysis of the variance (ANOVA) was performed for the comparison of physical and physiological parameters between playing position in different leagues. T-test not paired was carried out to all comparisons. Significance was set at $\mathrm{p}<0.05$.

\section{Results}

\subsection{Age and Anthropometrics Parameters}

No significant difference in age was found between soccer players of L1 and those of L2 and that whatever the position. According to the general comparison, player of L1 were significantly taller $(\mathrm{P}<0.01)$ and heavier $(\mathrm{P}<0.001)$ than those of L2 (Table 1). As regard to the positions only the MF of L1 were significantly $(\mathrm{p}<0.01)$ taller than those of L2 while DF $(\mathrm{p}<0.05)$ and $\mathrm{MF}(\mathrm{p}<0.01)$ of $\mathrm{L} 1$ were heavier $(\mathrm{P}<0.001)$ than those of L2.

Table 1. Comparison of anthropometrics characteristics of Cameroonians soccer players according to the leagues and posts.

\begin{tabular}{|c|c|c|c|c|c|c|c|c|c|}
\hline & \multirow{2}{*}{ Position } & \multicolumn{3}{|l|}{ L1 } & \multicolumn{3}{|l|}{ L2 } & \multirow{2}{*}{$\begin{array}{l}P \\
\text { value }\end{array}$} & \multirow{2}{*}{ Decision } \\
\hline & & $\mathbf{n}$ & Mean & SD & $\mathbf{n}$ & Mean & SD & & \\
\hline \multirow{5}{*}{ Age } & Total & 91 & 23.3 & 3.6 & 84 & 23.6 & 4.1 & 0.62 & $\mathrm{~ns}$ \\
\hline & GK & 13 & 24.0 & 3.1 & 12 & 23.7 & 3.7 & 0.80 & ns \\
\hline & DF & 21 & 24.1 & 3.1 & 28 & 24.4 & 4.1 & 0.73 & ns \\
\hline & MF & 20 & 23.8 & 4.4 & 29 & 23.9 & 4.0 & 0.87 & ns \\
\hline & AT & 31 & 22.0 & 3.3 & 14 & 21.2 & 4.2 & 0.50 & $\mathrm{~ns}$ \\
\hline \multirow{5}{*}{ Height } & Total & 91 & 179.1 & 7.2 & 84 & 175.8 & 7.3 & .01 & $* *$ \\
\hline & GK & 13 & 182.4 & 6.2 & 12 & 181.4 & 6.8 & 0.48 & ns \\
\hline & $\mathrm{DF}$ & 21 & 180.6 & 6.4 & 28 & 178.2 & 6.1 & 0.18 & $\mathrm{~ns}$ \\
\hline & $\mathrm{MF}$ & 20 & 178.3 & 6.9 & 29 & 172.3 & 7.1 & 0.01 & $* *$ \\
\hline & AT & 31 & 176.3 & 8.1 & 14 & 174.0 & 5.9 & 0.72 & ns \\
\hline \multirow{5}{*}{ Weight } & Total & 91 & 76.0 & 7.6 & 84 & 72.2 & 8.2 & .001 & $* * *$ \\
\hline & GK & 13 & 81.2 & 5.9 & 12 & 79.4 & 6.9 & 0.48 & ns \\
\hline & $\mathrm{DF}$ & 21 & 77.9 & 8.2 & 28 & 73.4 & 7.3 & 0.02 & $*$ \\
\hline & MF & 20 & 74.6 & 6.2 & 29 & 68.4 & 7.6 & 0.01 & $* *$ \\
\hline & AT & 31 & 72.6 & 7.2 & 14 & 71.7 & 8.1 & 0.72 & ns \\
\hline
\end{tabular}

$\mathrm{L} 1=$ league $1 ; \mathrm{L} 2=$ league $2 ; \mathrm{SD}=$ standard deviation ${ }^{*}=$ significant difference $\mathrm{P}<0.05 ;{ }^{* *}=$ significant difference $\mathrm{P}<0.01{ }^{* * *}=$ significant difference $\mathrm{P}<0.001$.

\subsection{Sprint Ability}

GK, DF, MF and AT of L1 were faster $(\mathrm{P}<0.001)$ than L2 players at the same post on 10 and $20 \mathrm{~m}$ (Figure 1a). No difference in sprint was observed between GK, DF or MF of L1 and L2 on 30 and 40m. The only significant differences in sprint $(\mathrm{P}<0.001 ; \mathrm{P}<0.01$, respectively) were observed between AT with higher performance for those of L1. Overall (figure 1b), L1 players are faster than those of L2 over all distances but the difference is only significant $(\mathrm{P}<0.05)$ over $10 \mathrm{~m}$. 

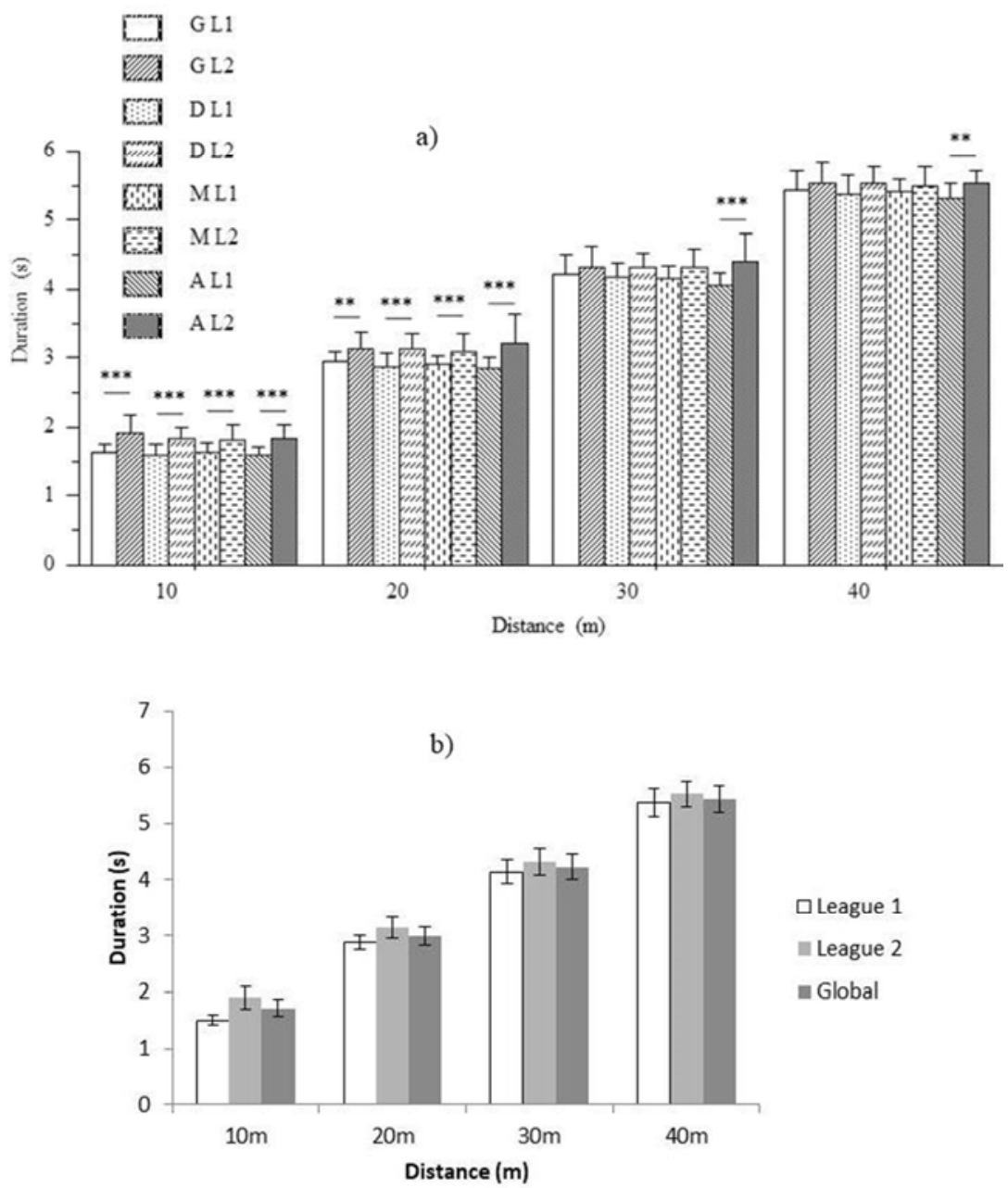

Figure 1. Comparison of sprints performance of Cameroonian soccer players according to the posts (a) and leagues (b).

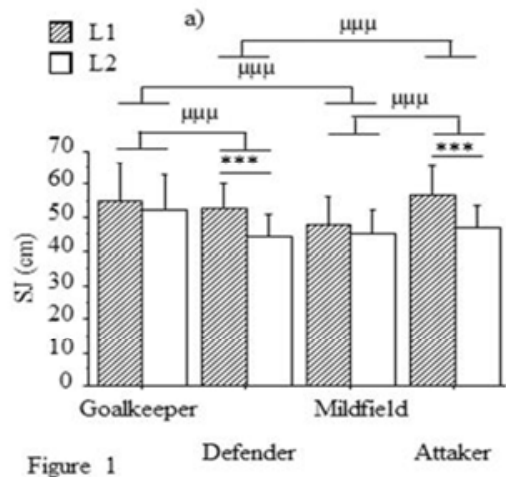

c)

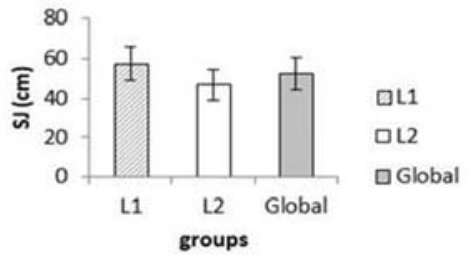

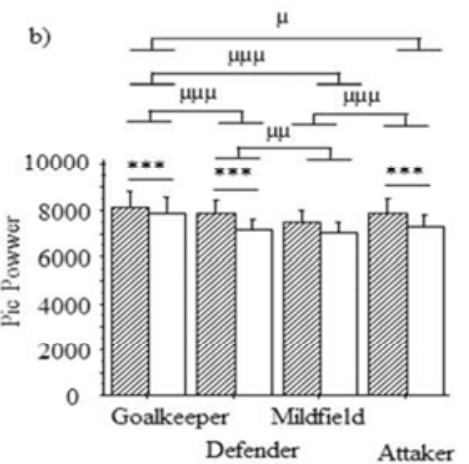

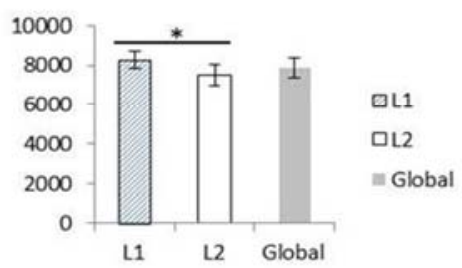

Figure 2. Comparison of Squat jump performance $(a, c)$ and pic power of legs $(b, d)$ of Cameroonian soccer players according the leagues and posts. 


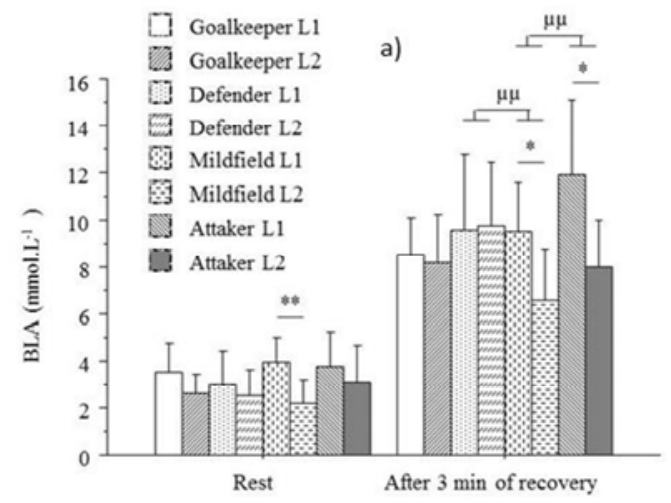

b)

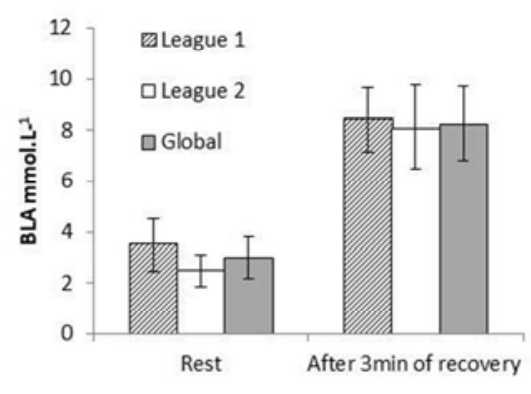

Figure 3. Comparison of blood lactate accumulation (BLA) of Cameroonian soccer players according to the post (a) and leagues (b).
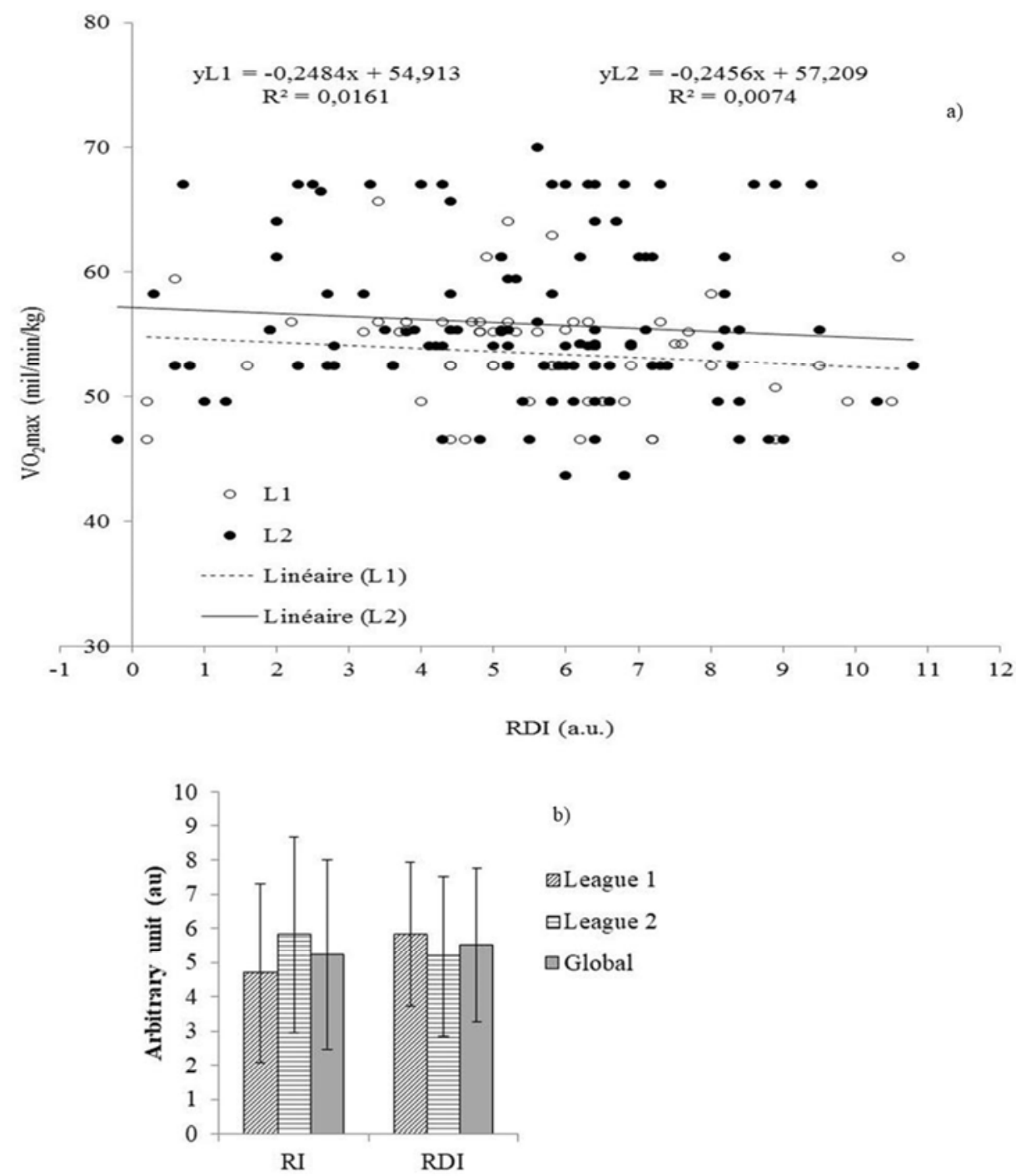

RI; Ruffier index; RDI: Ruffier and Dickson index

Figure 4. Comparison of Ruffier and Ruffier and Dickson index of Cameroonian soccer players according to the leagues (a) and Correlation between VO ${ }_{2 m a x}$ and Ruffier and Dickson Index for L1 and L2 (b).

\subsection{Vertical Jump and Power of Leg}

Figure 2a shows the performance of squat jump (SJ) with significant higher values $(\mathrm{P}<0.001)$ among $\mathrm{DF}$ and $\mathrm{AT}$ of $\mathrm{L} 1$ compared to those of L2. However, no difference was found between GK or MF of the two leagues in $\mathrm{SJ}(\mathrm{cm})$ performance. GK and AT jump were higher than those of $\mathrm{DF}(\mathrm{P}<0.001)$ and $\mathrm{MF}(\mathrm{P}<0.001)$ in $\mathrm{SJ}(\mathrm{m})$. Figure $2 \mathrm{~b}$ shows the comparison of peak power of lower limbs. GK, DF and AT of L1 had 
significant higher power $(\mathrm{P}<0.001)$ compared to those of L2. However, no difference $(\mathrm{P}>0.05)$ was observed between the MF of the two leagues in peak power. The peak power was significantly greater among GK than in $\mathrm{DF}(\mathrm{P}<0.001), \mathrm{MF}$ $(\mathrm{P}<0.001)$ and AT $(\mathrm{P}<0.05)$ for both leagues. Similarly, for both leagues, AT $(\mathrm{P}<0.001)$ and $\mathrm{DF}(\mathrm{P}<0.01)$ had higher peak power than MF. Comparison of vertical jump performance between leagues (figure $2 \mathrm{c}$ and $\mathrm{d}$ ) did not reveal any significant difference in score, but in terms of leg power, L1 players are significantly more powerful than L2 players.

\subsection{Blood Lactate Accumulation}

At rest, BLA was significantly higher $(\mathrm{P}<0.01)$ in the MF of L1 compared to those of L2 (figure 3a). Three minutes after the exercise, BLA was significantly higher in MF $(\mathrm{P}<0.01)$ and AT $(\mathrm{P}<0.01)$ of L1 compared to those of L2. However, according to the playing positions, BLA were lower in MF compared to those of DF $(\mathrm{P}<0.01)$ and AT $(\mathrm{P}<0.01)$. In figure $3 \mathrm{~b}$, the maximum oxygen consumption $\left(\mathrm{VO}_{2 \max }\right)$ was significantly higher $(\mathrm{P}<0.05)$ among AT of L2 compared to those in $\mathrm{L} 1 . \mathrm{VO}_{2 \max }$ was significantly lower among GK than among DF $(\mathrm{P}<0.01)$, MF $(\mathrm{P}<0.05)$ and AT $(\mathrm{P}<0.01)$ for both leagues. By comparing the overall blood lactate data at rest and after recovery, no significant difference was found between leagues, and even with the overall value.

\subsection{Correlation Between $V \mathrm{O}_{2 \max }$ and Heart Rate Parameters}

In figure $4 \mathrm{a}$, weak relationships were found between $\mathrm{VO}_{2 \max }$ and RDI. Players of L2 had a better $\mathrm{VO}_{2 \max }$ than those of L1, but also a great adaptability to the effort. The number of players in L2 with both an average heart and a $\mathrm{VO}_{2 \max }$ above $60 \mathrm{ml} / \mathrm{min} / \mathrm{kg}$ was higher compared to that of L1. The comparison of the data of the Ruffier index as well as that of Ruffier and Dickson is presented in figure $4 \mathrm{~b}$; it emerges that, in view of the average values of the Ruffier index, players of L1 have a solid heart compared to those of L2. However the difference is not significant. Ruffier and Dickson's index values told us that players in two leagues have a similar level of adaptability to effort.

\section{Discussion}

The average age of soccer players of L1 was not significantly different to that ofL2 (Table 1). Nevertheless, this result shows that player of the Cameroonian elite soccer are younger than the Norwegian (25.8 years) and French (26.1 years) players [13]. They are also younger than Nigeria players in 2018 world cup (25,5 years) [16], but of the same age range with the Scandinavian (23.0 years) players [13]. The youngest of Cameroonian soccer players may be a contributing factor to endurance performance since Toth et al.(1994) [17] showed that the peak oxygen consumption declined with age. The fact that no difference in age was observed between L1 and L2 players suggest no substantial difference between the players of the two leagues as far as the endurance performance is concerned. The average of height in L1 players was significantly higher than in L2 players. However, these values were lower compared to the average values of European professional soccer players $(181.1 \pm 5.8 \mathrm{~cm})[18]$ as well as the young soccer players of France $(181.5 \pm 6.0 \mathrm{~cm})$ [19] and the world average height of players at the last soccer world cup Russia 2018 (1,82m) [20]. In L1, the goalkeepers were the tallest, followed by the defenders, the midfields and attackers. These data are somehow in accordance with those of Alpay [21], who showed the goalkeepers to be tallest followed by the defenders, attackers, and midfielders. This differential distribution of height according to the playing position can be justified by the fact that goalkeepers, defenders and attackers compete more for aerial balls during matches than midfielders. In Cameroon leagues, attackers are smaller than other players. This is probably one of the weak morphological characteristics as it cannot allow them to win aerial duels against taller defenders. The height and weight of L1 players were better than those of L2, these anthropometrics characteristics were still very weak compared to the average of the players of the last 2018 world cup in Russia [22]. Weight and height therefore constitute a fundamental parameter in the recruitment of players within the elite in Cameroon.

The comparison of 10, 20, 30, and $40 \mathrm{~m}$ sprints performance of Cameroonian professional soccer players according to their leagues and posts showed the goalkeepers, defenders, midfielders and attackers ofL1 to be faster than those of L2 over 10 and $20 \mathrm{~m}$ (figure 1a). The only significant differences at 30 and $40 \mathrm{~m}$ sprints were observed between attackers with good sprints for those of L1. At all distances, attackers appeared to be the fastest players. Significant difference found between attackers and midfielders and not between attackers and defenders was expected because attackers have to be fast if they want to pass defenders, and defenders have to be fast if they want to stop attackers in their intention to score a goal [4]. The lack of difference in sprint performance observed between goalkeepers, defenders or midfielders of L1 and those of L2 at distances of 30 and $40 \mathrm{~m}$ was reported by Gil et al.[23]. These authors found the attackers to be faster than defenders and midfielders on $30 \mathrm{~m}$. Goalkeepers had lower sprint than their counterparts as previously demonstrated by Gaurav et al. [24]. The players of the present study had better results than those of France [25]; this is due to their young age.

A comparison of the performance between players from Cameroon's two professional leagues revealed significant speed over all distances $(10 \mathrm{~m}, 20 \mathrm{~m}, 30 \mathrm{~m}, 40 \mathrm{~m})$ of $\mathrm{L} 1$ players compared to L2 players (figure 1b). By comparing these results of the sprint tests with the results of other studies, we can conclude that players in the present study performed better than the French [26], Norwegian [27], Germans [28] and English [29]. When comparing these results to other studies, we need to be very careful as there are many differences in study design and data collection. On the other hand, a good linear speed performance in football could not 
lead to hasty conclusions as it would have to be combined with agility tests to be sure of the good speed performance of Cameroon's elite footballers.

In Cameroon soccer leagues, the performance of SJ (m) are significantly higher $(\mathrm{P}<0.001)$ among defenders and attackers of L1 compared to those of L2. Goalkeepers and attackers jumped higher than defenders $(\mathrm{P}<0.001)$ and midfielders $(\mathrm{P}<0.001)$ (figure $2 \mathrm{a})$. These data are better than those of Croatian soccer players [4] Portuguese, Italian, Spanish, Norwegian and Scottish soccer players [27, 30, 31]. It appears that Cameroon soccer players have a larger potential in anaerobic power than players from Portugal, Italy, Spain, and Turkey [30].

In L1 and L2, the peak power in lower limbs were significantly greater among goalkeepers than in defenders $(\mathrm{P}<0.001)$, midfielders $(\mathrm{P}<0.001)$ and attackers $(\mathrm{P}<0.05)$ because anaerobic power manifested through the vertical jump is essential for successful goalkeeping [4]. However, the peak power were similar in attackers $(\mathrm{P}<0.001)$ and defenders $(\mathrm{P}<0.01)$ and higher than those of midfielders (figure $2 b$ ) dues to the use of this quality during aerial ball. The good physical performance of Cameroon elite soccer players (L1) reveals that, in addition to being tall and heavy, players must also have a good burst of speed and be strong enough in the legs.

The performances of Cameroonian soccer players in the squat jump testand pic power of legs revealed a clear superiority to those of the L1 (figure 2c and 2d). This performance, closely related to aerobic power, are better than those of Croatian footballers who, according to Sporis et al. [4]; also better than those of Portuguese, Italian, Spanish, Norwegian and Scottish footballers [27, 30-32]. Cazorla in 1998 [33] had placed the average vertical rebound performance at $62.76 \mathrm{~cm}$ and the maximum performance at $82.50 \mathrm{~cm}$. The performances of Cameroon professional soccer players (L1 and L2) are therefore low compared to the average value according to Cazorla [33]. It appears that Cameroonian football players have a greater anaerobic potential than players from Portugal, Italy, Spain and Turkey $[30,32]$.

Most action is performed in aerobic conditions by anaerobic activities, which make a difference between winning and losing. Most studies present the BLA values at the end of the first and second half of a soccer game [34, 35]. In this study, BLA was measured before and after the maximal exercise test. The higher BLA found in midfielders $(\mathrm{P}<0.01)$ and attackers $(\mathrm{P}<0.01)$ of $\mathrm{L} 1$ compared to those of L2 could show the higher performance of these players in L1. The higher BLA in midfielders compared to those of defenders $(\mathrm{P}<0.01)$ or attackers $(\mathrm{P}<0.01)$ (figure $3 \mathrm{a})$ in each league could be explained also by the great distance covered by the midfielders during matches. In Cameroon league, midfielders have a great capacity of recuperation than other players. They are the shortest players compared with the other positional roles. Moreover, midfielders cover far greater distances as compared with attackers and defenders. In the phase of attack, midfielders take a ball to the opponent's half, whereas the defenders, in most cases, make a slight shift forward, and the attackers wait for the ball from the midfielders. In the defensive phase, attackers run, midfielders run back, and the defenders wait for the opposing players. The specific role of midfielders on the team could be responsible for their physiological characteristics. Nevertheless, lack of height is not in itself a bar to success in soccer; it represents just one of the criteria for positional role selection [4]. Cameroon team with poor anthropometric and physical characteristics could not win many matches and therefore cannot have a good ranking at the end of the sports season [10]. The fact that the BLA after the recovery were better in L2 than in L1 players (figure 3b) allows us to note that the recovery capacity is not a criterion entering the selection of elite soccer players in Cameroon. According to Santos-Silva et al.[6], better or worse aerobic profiles according to game positions in soccer players do not influence peak lactate levels following high-intensity exercise.

$\mathrm{VO}_{2 \max }$ of Cameroonian L1 players $(53.8 \pm 4.3 \mathrm{~mL} / \mathrm{min} / \mathrm{kg})$ less than those of the world top football players (55 to 67 $\mathrm{mL} / \mathrm{kg} / \mathrm{min}$ ) [36] could explained the lower resistance of the national team during competitions.

The correlation between RDI and $\mathrm{VO}_{2 \max }$ in this study for L1 and L2 showed the coefficient of determination tends to 0 (figure 4a). Therefore, the scatter plot around the regression line $\mathrm{R}^{2}$ varied between 0 and 1 . In the present study, too weak relationships were observed between $\mathrm{VO}_{2 \max }$ and RDI of L1 and L2 soccer players.

Ruffier and Dickson index between 0 and 10 for all players in both leagues showed the players of both leagues to have robust heart. Players of L1 had a strong heart compared to those of L2 (figure 4b). This situation can be explained by the intensity and the volume of the training in L1 which would be higher than in L2. Moreover, this cardiac robustness would also explained the speed performances of the players of L1 because with a robust heart, the sportsman would produce good performances during anaerobic exercises. L2 players however had a similar level of adaptability to effort as players from L1, this can be explained by the fact that in L2 players are a little younger than those of L1.

\section{Conclusion}

The aim of the present study was to compare physical and physiological characteristics of Cameroon professional soccer players according to the level (leagues 1 and 2) and their positions. The height and weight of L1 players were better than those of L2, it were still very weak compared to those of players of the major European leagues. The speed test showed the superiority of L1 players at all distance. The endurance capacity was weak in L1 than in L2. However, L1 soccer players had a good recovery capacity than those in L2. Following the playing positions, the goalkeepers were the tallest, heaviest and slowest with a low recovery capacity compared to other players. Players of L1 certainly had better 
physical parameters compared to those of L2 and lower physiological response but these parameters were still very insufficient compared to the players of the great European championships.

\section{Acknowledgements}

Authors wish to thank all individuals who participated in the achievement of this study. A special thanks to team coaches the help.

\section{References}

[1] Carvalho HM, Bidaurrazaga-Letona I, Lekue JA, Amado M, Figueiredo A J, \& Gil SM. Physical growth and changes in intermittent endurance run performance in young male Basque soccer players. Res Sport Med. 2014; 22: 408-424.

[2] Akenhead R, Hayes PR, Thompson KG, French D. Diminutions of acceleration and deceleration output during professional football match play. J Sci Med Sport. 2013; 16: $556-561$.

[3] Sylejmani B, Maliqi A, Gontarev S, et al. Anthropometric characteristics and physical performance of young elite kosovo soccer players. Int J Morphol. 2019; 37 (4): 14291436. doi: 10.4067/S0717-95022019000401429

[4] Sporis G, Jukic I, Ostojic SM, and Milanovic D. Fitness profiling in soccer: Physical and physiologic characteristics of elite players. J Strength Cond Res. 2009; 23 (7): 1947-1953.

[5] Da Silva CD, Bloomfield J, Marins JCB. A review of stature, body mass and maximal oxygen uptake profiles of U17, U20 and first division players in Brazilian soccer. J Sport Sci Med. 2008; 7 (3): 309-319.

[6] Santos-Silva PR, Pedrinelli A, Greve JMD. Blood lactate and oxygen consumption in soccer players: comparison between different positions on the field. Med Express. 2017; 4 (1): 1-6. doi: 10.5935/medicalexpress.2017.01.02

[7] Booysen MJ, Gradidge PJL, Constantinou D. Anthropometric and Motor Characteristics of South African National Level Female Soccer Players. J Hum Kinet. 2019; 66 (1): 121-129. doi: 10.1515/hukin-2017-0189.

[8] Booysen MJ, Bentel D, Harry K, Gradidge PJL. Anthropometric variables and physical fitness characteristics of male South African semi-professional footballers. South African J Res Sport Phys Educ Recreat. 2018; 40 (2): 11-21.

[9] Kubayi A, Paul Y, Mahlangu P, Toriola A. Physical Performance and Anthropometric Characteristics of Male South African University Soccer Players. J Hum Kinet. 2017; 60 (1): 153-158. doi: 10.1515/hukin-2017-0098.

[10] Fomini TJ, Nguelefack TB, Assomo NPB, et al. Anthropometric and physical characteristics in league 1 soccer players on the ranking of teams in Cameroon Anthropometric and physical characteristics in league 1 football players on the ranking of teams in Cameroon. 2019; GSJ 7 (12): 1186-1206.

[11] Rosch D, Hodgson R, Peterson L, et al. Assessment and evaluation of football performance. Am J Sports Med. 2000; 28 (5): $29-39$
[12] Loturco I, Jeffreys I, Abad CCC, et al. Change-of-direction, speed and jump performance in soccer players: a comparison across different age-categories. J Sports Sci. 2019; 00 (00): 17. doi: 10.1080/02640414.2019.1574276https://doi.org/10.1080/0264 0414.2019.1574276.

[13] Chan HC, Fong DT, Lee JW, et al. Power and endurance in Hong Kong professional football players. Asia-Pacific J Sport Med Arthrosc Rehabil Technol. 2016; 5: 1-5. doi: 10.1016/j.asmart.2016.05.001

[14] Brocherie F, Girard O, Forchino F, et al. Relationships between anthropometric measures and athletic performance, with special reference to repeated-sprint ability, in the Qatar national soccer team. J Sports Sci. 2014; 32 (13): 1243-1254. doi: 10.1080/02640414. 2013.862840

[15] Pyne DB, Boston T, Martin DT, Logan A. Evaluation of the Lactate Pro blood lactate analyser. Eur J Appl Physiol. 2000; 82 (1-2): 112-116. doi: 10.1007/s004210050659

[16] Malécot APV. Quelle équipe est la plus jeune ou la plus grande de la Coupe du monde 2018? Le Monde 14 juin. 2018.

[17] Toth MJ, Gardner AW, Ades PA PE. Contribution of body composition and physical activity to age-related decline in peak $\mathrm{VO}_{2}$ in men and women. J Appl Physiol. 1994; 77: 647-652.

[18] Owen A, Wong del P PD and Dellal A. Effects of a periodized small-sided game training intervention on physical performance in elite professional soccer. J Strength Cond Res. 2012; 26: 2748-2754.

[19] Rebelo M, Smylie C, Macintosh S LR. Selected physical attributes of male soccer players: a comparative analysis. Afr $J$ Phys Heal Educ Recr. 2010; 16: 85e92.

[20] Bouthier B. Revue de statistiques sur les 32 sélections qui participent au Mondial du 14 juin au 15 juillet. Le Monde 14 juin. 2018.

[21] Alpay CB. Comparison of athletic performances of male soccer players with respect to their respective positions in game. Anthropol. 2016; 24 (2): 519-525.

[22] Musset M. Mondial 2018: taille, âge, pays, les 736 joueurs passés au crible. Sud Ouest 14 juin. 2018.

[23] Gil SM, Gil J, Ruiz F, et al. Physiological and anthropometric characteristics of young soccer players according to their playing position: relevance for the selection process. $J$ Strength Cond Res. 2007; 21: 438-445.

[24] Gaurav V, Singh A, Singh S. Comparison of selected physical fitness components among male football players of different playing positions. Turkish J Sport Exerc 2015; 17: 22. https://doi.org/10.15314/tjse.68533.

[25] Dellal A., Wong DP. Repeated sprint and change-of-direction abilities in soccer players: Effects of age group. $J$ Strength Cond Res. 2013: 2504-2508.

[26] Cometti G., Maffiuletti NA., Pousson M., Chatard, JC., \& Maffulli N. Isokinetic strength and anaerobic power of elite, subelite and amateur french soccer players. Int J Sports Med 2001; 22: 45-51.

[27] Hoff $\mathbf{J}$ and Helgerud J. Endurance and strength training for soccer players: physiological considerations. Sport Med. 2004; 34: $165-180$. 
[28] Kollath K and Quade E. Experimental measurements of the professional and amateur soccer players' sprinting speed. In: Science and Football II. Reilly, T, Clarys, J, and Stibbe, A. Eds London E FN Spon 1993: 31-36.

[29] Little Tand Williams A. Effects of differential stretching protocols during warm-ups on high-speed motor capacities in professional soccer players. J Strength Cond Res 2006; 20: 203-207.

[30] Gorostiaga EM, Izquierdo $M$, Ruesta $M$, et al. Strength training effects on physical performance and serum hormons in young soccer players. Eur J Appl Physiol. 2004; 91: 698707.

[31] Macmillan K, Helgerud J, Macdonald R, and Hoff J. Physiological adaptation to soccer specific endurance training in professional youth soccer players. Br J Sport Med. 2005; 39: 273-277.
[32] Garganta J, Maia J, Silva R, and Natal AA. comparison study of explosive leg strength in elite and non-elite young soccer players. In: Science and Football II. Reilly, T, Clarys, J, and Stibbe, A. Eds London Spon 1993: 304-306.

[33] Cazorla AG et Farhi. Football: exigences physiques et physiologiques actuelles. Rev EPS 1998; 273: 60-4.

[34] Bangsbo JC. Counterpoint: lactic acid accumulation is a disadvantage during muscle activity. J Appl Physiol 2006; 100 1412-3.

[35] Scott C. Contribution of blood lactate to the energy expenditure of weight training. J Strength Cond Res 2006; 20: 404-411.

[36] Metaxas T, Sendelides T, Koutlianos N and Mandroukas K. Seasonal variation of aerobic performance in soccer players according to positional role. J Sport Med Phys Fit. 2006; 46: $520-525$. 